\title{
Cruzamentos Vocabulares em Nivel Discursivo/ Textual: Efeitos Expressivos e Padrões Estruturais na Coluna de Agamenon Mendes Pedreira
}

\author{
Carlos Alexandre GONÇALVES \\ (Universidade Federal do Rio de Janeiro/CNPq) \\ Fábio Pereira de ASSUNÇÃO \\ (Fundação Educacional Unificada Campograndense)
}

Resumo: Neste estudo, demonstramos a eficácia do emprego de cruzamentos vocabulares, como 'Luísque' ('Lula' + 'uísque') e 'Jeguerino' ('jegue' + 'Severino'), na coluna de Agamenon Mendes Pedreira, publicada semanalmente no jornal $\boldsymbol{O}$ Globo. Procuramos mostrar o impacto expressivo dessas novas construções em nível discursivo/textual, ao mesmo tempo em que buscamos ressaltar o valor humorístico dos cruzamentos vocabulares na referida coluna.

Palavras-chave: Cruzamento vocabular; expressividade; humor.

Abstract: In this paper, We describe the efficacy of lexical blends, like 'Luísque' ('Lula' + 'uísque') and 'Jeguerino' ('Jegue' + 'Severino'), in Agamenon Mendes Pedreira's articles, published by $\boldsymbol{O}$ Globo once in a week. We show that lexical blends are constructions that cause an expressive impact in textual and discursive levels. We too argue that blends are a resource for the expression of humor in these articles.

Keywords: Lexical blend; expressivity; humor.

\section{Introdução}

Com o intuito de demonstrar a eficácia dos cruzamentos vocabulares em nível discursivo-textual, o corpus deste trabalho é a coluna de Agamenon Mendes Pedreira, publicada semanalmente no jornal O Globo. A partir das construções rastreadas ${ }^{1}$, procuramos

${ }^{1}$ Os dados foram coletados na coluna de Agamenon no período de um ano: de abril de 2005 a maio de 2006. Nosso corpus conta com cerca de cinqüenta formações e é com base nelas que a análise será desenvolvida. 
demonstrar, seguindo Basílio (2004, p. 1), que, nos cruzamentos bem sucedidos encontrados na referida coluna, há uma sensação de desvio, resultante de uma (re) construção vocabular em que uma das partes predica ou caracteriza a palavra básica hospedeira, freqüentemente de um modo inesperado e um tanto insólito.

O texto aparece divido como se segue: na próxima seção, caracterizamos, com base em Aranha e Madureira (2002), a figura do colunista Agamenon, um personagem criado pelo Grupo Casseta \& Planeta. $\mathrm{Na}$ seção seguinte, focalizamos os valores expressivos dos cruzamentos para, em seguida, apresentar as principais conclusões do estudo.

\section{Agamenon, o Homem}

A coluna dominical de Agamenon Mendes Pedreira, no jornal O Globo, tornou-se referência nacional para uma abordagem humorística sobre acontecimentos da sociedade brasileira, sejam eles sociais ou políticos. Apesar da visibilidade adquirida pela coluna, a trajetória do jornalista ainda pode ser considerada uma grande incógnita para a maior parte de seus leitores: os dezessete que o próprio afirma possuir.

Criação dos humoristas Hubert e Marcelo Madureira, do grupo Casseta e Planeta, Agamenon, assim como o Frankenstein de Mary Shelly, parece ter adquirido vida própria e se libertado do domínio de seus criadores, tornando-se, segundo palavras do jornalista Nelson Motta, um grande temor:

O maior temor de um homem de bem é ser elogiado por Agamenon. Ao contrário, celebrar o velho canalha é castigar o que há de pior e de mais corrupto no Brasil com a arma devastadora do riso, do deboche e do escárnio. (O Globo, $2^{\circ}$. Caderno, 25 de maio de 2006)

Como forma de ressaltar esse deboche, Agamenon concede uma entrevista exclusiva a si mesmo em seu livro Agamenon, o homem e o minto para esclarecer sua origem. Essa entrevista exclusiva a si mesmo é justificada por Agamenon da seguinte forma: 
Só eu, Agamenon Mendes Pedreira, seria capaz de compreender esta personalidade complexa, este caráter duvidoso, este homem atormentado (porém macho) que sou eu mesmo". (ARANHA; MADUREIRA, 2002, p. 7)

Durante a entrevista, Agamenon revela de forma bem humorada e sarcástica fatos da sua infância pobre ao lado do pai, empresário do setor petroquímico e da construção naval; atribui ao fato de ter abandonado os estudos, conseguindo somente aprender a escrever, o talento para o jornalismo. Esse talento ainda é reforçado por algumas características pessoais, segundo palavras do próprio Agamenon:

Até hoje não sei ler. Mas como sempre fui um sujeito ignorante, prepotente, arrogante, mau-caráter e desonesto, achei que poderia me tornar um bom jornalista de imprensa. (ARANHA; MADUREIRA, 2002, p. 8)

Agamenon também atribui grande parte de seu sucesso à esposa Isaura e ao doutor Jacintho Leite Aquino Rego, um dos colaboradores de sua coluna e clínico pessoal do jornalista. Conforme nota de capa do livro,

Agamenon, com seu estilo inconfundível, conquistou leitores de todas as tendências políticas, culturais e sexuais. Não há como resistir às suas tiradas engraçadas. Agamenon fez da picaretagem um trunfo". (ARANHA; MADUREIRA, 2002, Quarta Capa)

Em sua coluna dominical em O Globo, Agamenon demonstra sua destreza por meio de uma linguagem simples, voltada para descrever fatos horrendos da sociedade brasileira. A necessidade de conscientizar todas as camadas da população sobre acontecimentos que requerem um razoável conhecimento intelectual leva o autor a utilizar o humor como principal recurso em seus textos.

Agamenon aborda assuntos econômicos e políticos valorizando o que há de mais grotesco em seus conteúdos. Após determinar o foco a ser explorado, ele o suaviza com expressões de amplo conhecimento da população, tornando o tópico abordado mais acessível e atraente para todos. 
Além de expressões tipicamente populares, Agamenon utiliza outro recurso que lhe permite atingir o tom de ironia e de humor necessários para estabelecer um texto dinâmico, extremamente exigido no mundo moderno: um processo de formação de palavras conhecido na literatura morfológica do português como cruzamento vocabular (SANDMANN, 1990), palavra-valise (ALVES, 1989) ou portmanteau (SÂNDALO, 2001).

O cruzamento vocabular (doravante CV) constitui um fato gramatical que contribui para o estilo irônico e despojado da coluna, pois, através da interseção / fusão de palavras, Agamenon consegue criar o ambiente humorístico necessário, envolvendo palavras, em sua maioria, sem relação fonológica e / ou semântica, a exemplo de 'mensalácio' ( $<<$ mensalão + Inácio).

$\mathrm{Na}$ próxima seção, interessa-nos investigar os efeitos semântico-pragmáticos dos cruzamentos criados por Agamenon para caracterizar os personagens envolvidos em sua formação. Dessa maneira, focalizamos as formas cruzadas que envolvem um antropônimo, de modo a ressaltar de que maneira se manifestam as relações de predicação envolvidas nos CVs da coluna.

\section{Valores expressivos dos cruzamentos na coluna}

Em linhas gerais, os CVs da coluna de Agamenon buscam retratar acontecimentos políticos e sociais, abordando os fatos de forma constrangedora para os personagens, mas criando um fato geralmente humorístico para o leitor. É necessário observar, no entanto, que a força humorística dos cruzamentos vocabulares vem de uma fonte dupla, já que a quebra não é apenas conceptual, mas também (ou talvez, sobretudo) morfológica (BASÍLIO, 2005, p. 2).

CVs não são sempre humorísticos, mas a principal motivação para a sua existência é o poder expressivo (BASÍLIO, 2005, p. 2). Essa força expressiva pode ser observada na abordagem dispensada às questões políticas. Devido aos grandes escândalos envolvendo o governo do presidente Luís Inácio Lula da Silva, a coluna de Agamenon obteve farto material para a construção de cruzamentos, podendo esse material ser distribuído em três grandes grupos:

(a) o das formas que têm por base o segundo nome do presidente, Inácio; 
(b) o das formas criadas em função do primeiro nome do presidente, Luís; e, por fim,

(c) o das palavras construídas a partir de nomes de pessoas, empresas e partidos políticos participantes de escândalos de corrupção envolvendo o atual governo. Comecemos pelas formações criadas a partir de Inácio.

A crise vivida pelo governo Lula durante o ano de 2005 e a eterna afirmativa do presidente em desconhecer os fatos ocorridos levaram à produção de cruzamentos a partir do sobrenome Inácio. $\mathrm{Na}$ tentativa de ridicularizar a figura do presidente, o sobrenome Inácio serviu de base para outras palavras agirem de forma predicativa, tentando, através da produção de um novo vocábulo, apontar os defeitos do atual chefe da nação.

O êxito da formação desses novos vocábulos depende das possibilidades fonológicas de incorporação (GONÇALVES, 2005). A predicação será tanto mais feliz quanto menor for a interferência fonológica das formas de base, pois a construção morfológica resultante deve garantir a evocação do significado predicativo acoplado ao significado da palavra-matriz que constitui o núcleo da formação, no caso, um substantivo próprio.

Sendo assim, Agamenon produz novos vocábulos por meio de interferências predicativas à palavra base. A menção à figura do presidente é perfeitamente perceptível, pois, no resultado desses cruzamentos, conserva-se grande parte da estrutura-base Inácio. Como forma de reforçar a relação entre essas novas formações e a figura do presidente, Agamenon as posiciona no interior do nome completo de Lula, na posição original da palavra-base. Cabe salientar que para compreender os CVs criados por Agamenon, é necessário ter um forte conhecimento do mundo político para atingir a totalidade do efeito expressivo. É só a partir desse conhecimento que a predicação surte pleno efeito.

Gonçalves (2004, p. 16), assim como Basílio, aborda a necessidade de os CVs apresentarem-se dentro de um contexto, uma vez que são criações típicas da modalidade oral. Para compreender esse tipo de construção, é necessário resgatar as pistas estruturais fornecidas e conectá-las a informações contextuais, culturais e / ou de conhecimento partilhado. 
A partir dos exemplos a seguir, pode-se comprovar a tentativa de comprometer a figura do presidente com todos os acontecimentos políticos da nação. Tal ocorre com "mensalácio" ( $<<$ Mensalão + Inácio). Esse CV foi um dos mais freqüentes na coluna, durante o período consultado. Agamenon, em nenhum momento, afirma diretamente sobre o envolvimento do presidente Lula no escândalo do mensalão. No entanto, deixa isso implícito através do CV "Mensalácio" - utilizando a palavra mensalão como elemento predicativo do sobrenome do presidente - incorporado ao nome completo do presidente, conforme o observado em O Globo de 21 de agosto de 2005:

A CEGONHA E O COELINHO da Páscoa não acreditam na inocência do presidente Luís Mensalácio Lula da Silva. Só o Papai Noel acredita, mas aí não vale. O Bom Velhinho é do PT e só se veste de vermelho.

Assim como "Mensalácio", o CV "Viajandácio" é uma produção constante na coluna de Agamenon. Esse CV apresenta-se como justificativa para os problemas da nação e para a total inércia do presidente, pois, segundo o autor, este pensa somente em viajar pelo mundo. $\mathrm{O}$ interessante na produção desse $\mathrm{CV}$ é o seu surgimento a partir de uma gíria ("viajandão") muito comum no cenário carioca, a qual classifica a pessoa que viaja constantemente, predicando o sobrenome do presidente e intensificando sua ausência no cenário nacional, como caracterizado, em O Globo de 29 de maio de 2005, no trecho:

O presidente Luís Viajandácio Lula da Silva não está nem aí para a corrupção que come solta no Brasil e continua acumulando milhagens..

Os CVs "Stalinácio", "Populácio" e "Filhácio" estão ligados à forma de conduzir a política, adotada pelo presidente Lula. Agamenon busca, através dessas construções, criticar a administração do presidente, enfocando posições extremistas, populistas e nepotistas existentes no governo. 
No CV "Stalinácio" ( $<<$ Stalin + Inácio), observa-se a tentativa de associar as ações do presidente Lula como sendo inspiradas nos ideais do governante russo Stalin, notável por sua conduta política anti-capitalista e centralizadora. Esse fato pode ser observado de forma direta em O Globo de 23 de outubro de 2005 no trecho:

O presidente Luís Stalinácio Lula da Silva aproveitou que estava em Moscou para visitar a múmia de Lênin, com quem combinou os novos passos na luta contra a política imperialista norte-americana na América Latina.

Quanto aos CVs "Populácio", "Filhácio" e "Empregácio", percebe-se a intenção de demonstrar o uso dos recursos públicos por parte do presidente, favorecendo a si próprio e a seus parentes. $\mathrm{Na}$ construção "Populácio", Agamenon insinua sobre a tentativa de ações populistas. O presidente Lula manipularia a população, através de feitos e medidas com características eleitorais, para interromper a criação de uma Comissão Parlamentar de Inquérito (CPI). Tal fato é apresentado de forma mais contextualizada em O Globo de 7 de agosto de 2005, no trecho:

IRRITADO COM as acusações de corrupção contra o seu governo, o presidente Luís Populácio Lula da Silva está mobilizando e incitando as massas para preparar a gigantesca pizza da CPI.

Ainda em relação à política de Lula, Agamenon ressalta, através das construções "Filhácio" e "Empregácio", o uso da máquina pública pelo presidente para favorecer seu filho. Ambos os CVs estão ligados à ascensão financeira meteórica do filho de Lula, conforme pode ser constatado em um dos títulos da coluna de Agamenon: "Fábio Filhácio Lula da Silva, o Lulinha", de O Globo de 17 de julho de 2005.

$\mathrm{Na}$ coluna, alguns CVs remetem a características pessoais do presidente Luís Inácio Lula da Silva. A partir da base "Inácio", Agamenon incorpora palavras com conteúdo depreciativo na construção do novo vocábulo, para apontar defeitos em Lula. Essas construções, localizadas na posição da palavra-base no nome completo do presidente, reforçam a intenção do autor. Em Luís "Manguácio" 
Lula da Silva, Agamenon revela o gosto do presidente pela bebida, utilizando a expressão "manguaça" - gíria utilizada para designar bebida alcoólica - incorporada ao nome Inácio. Esse gosto de Lula pela bebida, em especial pela cachaça, faz Agamenon relacionar a imagem do presidente a uma bebida típica do Brasil, a caipirinha (feita à base de cachaça), conforme pode ser observado em Luís Caipirinácio Lula da Silva, de O Globo de 12 de dezembro de 2005, título de uma das colunas de Agamenon, cujo texto atribui à cachaça todos os devaneios e vaidades do governo.

Já em Luís Falácio Lula da Silva e Luís Emgambelácio Lula da Silva, as palavras "falador" e "emgambelador", incorporadas ao nome "Inácio", passam a imagem de um presidente sem compromisso com o país e criador de falsas promessas. Diferentemente dos itens anteriores, nos quais se percebe uma crítica mais ácida e expressiva aos desmandos da nação, observa-se, nessas últimas construções, um tratamento mais grotesco e, ao mesmo tempo, humorístico de possíveis "desvios" na conduta da pessoa do presidente, como sua atração pela bebida alcoólica. Como assinala Basílio (2005, p.2), no Cruzamento Vocabular típico, de caráter humorístico ou pelo menos retórico, a parte inesperada predica de modo forte e grotesco a parte básica.

Assim, o cruzamento de maior êxito é aquele em que não apenas a reestruturação morfológica força uma reestruturação da projeção conceitual; mais do que isto, nos cruzamentos com mais êxito a projeção conceitual a ser reestruturada vai por um caminho não apenas inesperado, mas insólito, embora inexorável (BASÍLIO, 2005, p. 2).

Conforme mencionado anteriormente, é notório o gosto do presidente pela bebida. Devido a esse conhecimento por parte da imprensa, outro escândalo bastante explorado estava relacionado a caixas de uísque. Segundo notícias divulgadas na imprensa brasileira, a campanha do presidente Lula teria sido financiada pelo dinheiro enviado por Cuba em caixas de uísque. Agamenon, dessa vez, utiliza o primeiro nome do presidente como elemento predicador na palavra-base uísque para a construção de um novo $\mathrm{CV}$.

O novo vocábulo, colocado na posição de elemento predicador no interior do nome completo do presidente, busca novamente associar o chefe da nação aos escândalos políticos e admitir 
o conhecimento dos fatos por parte dele, como pode ser caracterizado nesse parágrafo, escrito em O Globo de 20 de novembro de 2005:

Ao ouvir as insinuações de que recebeu dinheiro de Cuba embalado em caixas de bebida, o presidente Luísque Inácio Lula da Silva comentou curto e grosso: 'É rum, hem?'

Ao contrário do sobrenome Inácio, que serviu de base para a manifestação de diversos CVs, o nome Luís - como elemento predicador - teve sua aparição associada unicamente à palavra uísque, formando o CV "Luísque".

Durante o ano de 2005, o governo do presidente Luís Inácio Lula da Silva ficou marcado pela participação de pessoas de credibilidade e de competência duvidosas. $\mathrm{O}$ tratamento dado por Agamenon a essas pessoas foi o mesmo dispensado ao presidente Lula, com críticas vorazes e expressões jocosas para caracterizar o comportamento dos participantes do governo. $\mathrm{O}$ autor volta sua atenção para ministros, partidos políticos, colaboradores e empresas através da criação de CVs comprometedores. Devido ao grande material produzido por Agamenon, restringimo-nos, neste artigo, à análise de CVs com influência decisiva nos escândalos governamentais. O primeiro deles é "Merdonça" ( $<$ Merda + Mendonça).

O CV "Merdonça" faz referência ao organizador da campanha presidencial do presidente Lula, Duda Mendonça. A predicação da palavra "merda" no sobrenome "Mendonça" busca demonstrar as atitudes equivocadas do estrategista presidencial. Fato de ampla circulação na imprensa foi a prisão de Mendonça durante a participação em uma rinha de galos, conforme pode ser observado em Agamenon no trecho "Depois de uma reunião com Duda Merdonça, o presidente Luís Galinácio Lula da Silva resolveu partir pra a briga", de O Globo, de 17 de julho de 2005. Cabe salientar, nesse trecho, a presença do CV "Galinácio" (<< galinha + Inácio), caracterizando (i) a relação direta entre Duda Mendonça e o presidente e (ii) a interferência deste na solução do problema. Atente-se, ainda, para o fato de o cruzamento "Galinácio" apresentar a mesma pronúncia do substantivo 'galináceo', o que atenta, mais uma vez para o evento das rinhas de galos. 
Outro cruzamento envolvendo nome de pessoas ligadas ao governo é "Jeguerino" (<< Jegue + Severino). Personagem polêmico do governo Lula, o deputado Severino Cavalcanti ficou nacionalmente conhecido pelas decisões equivocadas e práticas protecionistas dos deputados corruptos, quando à frente do Congresso Nacional. Constantemente interpelado pela imprensa nacional, Severino, na maioria das vezes, comportava-se de forma evasiva, mostrando total desconhecimento quanto aos acontecimentos políticos da nação.

Agamenon, através do CV "Jeguerino", procura caracterizar o deputado como uma pessoa ignorante, fato constatado no trecho "O deputado Jeguerino Cavalcanti pede um tempo para pensar, coisa que ele nunca tinha feito antes", de O Globo, de 18 de setembro de 2005.

Também digna de nota é a construção "Rouberto" $(<<$ Roubo + Roberto). O deputado Roberto Jefferson, principal personagem dos escândalos envolvendo o governo Lula, foi quem denunciou a corrupção existente no Congresso Nacional, sendo o próprio um dos beneficiados. Notícias divulgadas pela imprensa destacavam o recebimento de quatro milhões de reais pelo deputado através de propina. O CV "Rouberto" reforça as ações escusas praticadas pelo deputado, como constatado em O Globo, de 18 de setembro de 2005 no trecho:

Todos esperavam que, no dia do seu discurso final no Congresso, Rouberto Jefferson fosse devolver a mala com quatro milhões de reais, conforme havia prometido.

O Partido dos Trabalhadores (PT), do presidente Luís Inácio Lula da Silva, foi o mais atacado durante os escândalos políticos, devido ao fato de grande parte de seus deputados e colaboradores estarem envolvidos no esquema de corrupção. O PT vangloriava-se por ser um partido ético, sem práticas de corrupção. Ao ser constatada a participação de integrantes da cúpula do partido em operações fraudulentas, essa imagem foi completamente abalada, tornando-se motivo de construções sarcásticas por parte da imprensa. Agamenon, em sua coluna, passa a designar o partido como o dos "trambicadores", reforçando a falta de ética e de responsabilidade com a nação. Em $\mathbf{O}$ Globo de 12 de junho de 2005, o autor satiriza a posição do partido 
quanto aos acontecimentos, explorando o CV "trambicadores" como justificativa para as práticas de corrupção do PT, conforme pode ser constatado no seguinte trecho:

Para dar uma satisfação à opinião pública, o Partido dos Trambicadores já nomeou a cleptomaníaca Hayde de América como nova tesoureira do PT.

A coluna de Agamenon aborda basicamente assuntos de cunho político. Contudo, sempre ocorrendo um fato relevante na sociedade brasileira, o autor procura emitir sua opinião sobre os acontecimentos. Em relação às questões sociais, há, nos CVs criados na coluna, a tentativa de expor ao ridículo as ações dos personagens envolvidos. Para isso, Agamenon utiliza mecanismos como (a) a construção de CVs com conotação sexual e (b) a construção de CVs envolvendo palavras com função depreciativa.

Os CVs com conotação sexual, doravante CVs sexuais, ridicularizam os acontecimentos ou personagens, associando-os a práticas sexuais, exploradas de forma jocosa no cenário brasileiro. Diversas palavras sofrem uma abordagem sexual por parte de Agamenon para representar a região do ânus. Essas palavras, utilizadas no sentido conotativo, estão quase sempre relacionadas a ações fracassadas. Em "Rosquinha", Agamenon faz referência à exgovernadora do Estado do Rio de Janeiro. A palavra "rosca", utilizada como sinônima de ânus, caracteriza o péssimo governo de Rosinha Matheus. Sendo assim, o CV criado a partir de "rosca" + "Rosinha" adquire um valor negativo, como pode ser observado em $\mathbf{O}$ Globo, de 26 de dezembro de 2005:

A cidade do Talo se parece muito com a cidade do Rio de Janeiro, com a vantagem de não ser governada pelo César Maia, nem pela Rosquinha Garotinho.

A forma em questão, dada a existência do substantivo graduado em diminutivo, só é entendida como cruzada em função de um contexto e através da expressão "Rosquinha Garotinha". Fora de contexto, tal forma não seria interpretada como resultado de um cruzamento, mas de uma derivação sufixal. 
A palavra "cu", forma chula também utilizada para representar a região do ânus, é utilizada por Agamenon para a construção de outros CVs. Em "currupção" ( $<<$ cu + corrupção) e "currompidos" ( $<<\mathrm{cu}+$ corrompido), o autor destaca a decadência moral e a falta de credibilidade existentes na capital do país. Esses CVs podem ser observados no trecho "Devido ao clima insalubre do Cerrado, a currupção é endêmica e é enorme a quantidade de indivíduos currompidos", de O Globo, de 12 de junho de 2005. Outra forma de explorar o ridículo em Agamenon é feita através dos órgãos masculino e feminino. Esse fato pode ser constatado em "boquetel" e "bucetante".

No CV "boquetel", Agamenon explora as construções "boquete" e "coquetel". A palavra "boquete" é uma forma chula utilizada para representar o sexo oral no órgão masculino; ao cruzá-la com "coquetel", estabelece-se uma prática grupal. O ridículo somente é estabelecido através do contexto, quando Agamenon relaciona "boquetel" a um banheiro masculino, conforme o trecho "No banheiro masculino, onde andava rolando um boquetel, encontrei vários cinéfilos ativos e passivos...", de $\mathbf{O}$ Globo, de 5 de fevereiro de 2006, dando a idéia de uma reunião de homossexuais.

Já no vocábulo "bucetante", a construção é totalmente eficaz somente observando-se o jogo de palavras existentes no trecho "... onde pretendo revelar detalhes picantes (e bucetantes também) da sociedade brasileira...", de O Globo, de 27 de novembro de 2005. Agamenon trabalha a parte inicial da palavra "picante" ([pica-]), a qual representa de forma chula o órgão sexual masculino; em seguida, ele incorpora a palavra "buceta", forma chula do órgão sexual feminino, ao final de uma palavra [X-nte]. Gonçalves e Almeida (2004) consideram esse tipo de construção como uma substituição sublexical, pois o alvo é apenas uma das palavras e a interseção das bases é ocasionada por uma reanálise intencional da forma de input, no caso, "picantes", reinterpretada como constituída morfologicamente da base \{pica\} + o sufixo - nte.

Cabe enfatizar tratar-se somente de um jogo de palavras criado pelo autor, pois entre a palavra "picante" e o órgão sexual masculino não há relação alguma, ao contrário de "bucetante", em que a intenção manifestada por Agamenon, comprovada através de contexto, é de estabelecer essa relação. 
As pessoas com uma imagem pública na sociedade também são alvo do sarcasmo e do humor característicos da coluna de Agamenon. Essas pessoas são caracterizadas, a partir de relações com seus nomes e / ou pertences materiais, por palavras que depreciam sua imagem perante os leitores. Tal é o caso da modelo Daniella Cicarelli, que foi uma personalidade bastante explorada pela mídia no ano de 2005. O casamento-relâmpago com o jogador Ronaldo e as vantagens financeiras obtidas com a união pela modelo levaram a imprensa a duvidar dos sentimentos de Daniella pelo jogador. Agamenon aborda o assunto através do CV "Ciscarelli". A produção do novo vocábulo pelas palavras "ciscar" e "Cicarelli" mostra a intenção do autor em estabelecer a união do casal como sendo um mero investimento financeiro por parte da modelo. A palavra "ciscar" faz referência ao uso conotativo da palavra "galinha", utilizada comumente para designar mulheres interesseiras e / ou de vida fácil. Por meio desse CV, Agamenon estabelece um padrão para a personalidade da modelo.

Outro acontecimento de repercussão nacional no ano de 2005, merecedor da atenção de Agamenon, foi a invasão da loja Daslu na cidade de São Paulo. Sob a suspeita de sonegação fiscal, a loja sofreu uma operação da Polícia Federal. Agamenon, como forma de confirmar a suspeita da imprensa quanto à evasão fiscal, cria o CV "Daslucro" ( $<<$ Daslu + lucro), reforçando assim, a expectativa sobre as práticas fraudulentas da empresa.

A vida social dos políticos também recebe comentários sarcásticos por parte de Agamenon. Em foco, como nos CVs com conotação sexual, estão o presidente Luís Inácio Lula da Silva e a exgovernadora do Rio de Janeiro, Rosinha Matheus.

A visita do presidente americano George W. Bush ao Brasil foi considerada por Agamenon como um grande encontro de "bestadistas". O CV criado a partir de "besta" e "estadistas" realça a opinião do autor em relação aos presidentes, como se observa no trecho "Um outro traço une os dois grandes bestadistas mundiais: Lula, assim como Bush, também não sabe falar Inglês" (O Globo, de 6 de novembro de 2005).

Quanto à governadora do Rio de Janeiro, Agamenon comenta uma foto divulgada na imprensa, mostrando a governadora em uma posição constrangedora durante o período de férias. A manchete criada pelo autor para a foto apresentava o CV "indiscroto" $(<<$ indiscreto 
+ escroto), reforçando a fragilidade e o ridículo do momento vivido pela governadora.

Como é comum no discurso de Agamenon, percebe-se um teor mais ácido na criação dos CVs envolvendo personalidades políticas, com palavras como "besta" e "escroto" fazendo parte do corpo do novo vocábulo.

$\mathrm{Na}$ próxima seção, analisamos alguns dos cruzamentos apresentados nesta parte do trabalho, observando a contraparte formal do fenômeno. Interessa-nos, portanto, investigar os padrões estruturais de que se serve Agamenon para formar os cruzamentos vocabulares.

\section{Padrões estruturais dos cruzamentos de Agamenon}

Os textos publicados por Agamenon na coluna dominical de $\mathbf{O}$ Globo constantemente apresentam uma afirmativa interessante a respeito do próprio autor: ele revela ter sido obrigado a abandonar os estudos, só conseguindo aprender a escrever. Essa colocação só poderia partir de alguém destinado a valorizar o emprego da ironia, do deboche e do escárnio em suas produções. Um exemplo dessa atitude é o emprego de construções "pouco valorizadas" para alguns gramáticos tradicionais de língua portuguesa (LIMA, 1975; CUNHA; CINTRA, 1980): os cruzamentos vocabulares.

Fusões vocabulares estão quase sempre presentes no texto de Agamenon, garantindo o efeito humorístico tão almejado pelo autor. Nesta parte do artigo, analisamos os processos utilizados por Agamenon na construção desses vocábulos, tendo como ponto de referência os conceitos estabelecidos por Gonçalves (2004, 2005, 2006) quanto aos padrões estruturais de cruzamentos.

Gonçalves (2004) descreve o CV como um fenômeno morfológico não-concatenativo em língua portuguesa, sendo caracterizado pela interseção de bases. De acordo com o autor, há dois padrões para cruzamentos no português do Brasil: (a) um para os casos em que as formas de base apresentam algum tipo de semelhança fônica e (b) outro, para aqueles em que elas são diferentes do ponto de vista segmental.

Ainda em relação à estrutura de cruzamentos, observa-se também a caracterização pelo fenômeno morfológico da ambimorfemia (PIÑEROS, 2002), que garante maior fidelidade às 
palavras que servem de base à formação: cruzamentos otimizam maximamente o compartilhamento de material fonológico, promovendo relação de um-para-dois entre forma cruzada e formas de input. A existência de segmentos ambimorfêmicos é um fator relevante na construção dos CVs. Gonçalves (2005, p. 145) faz a seguinte observação sobre as múltiplas relações de correspondência em seus estudos:

Múltiplas relações de correspondência viabilizam a sobreposição em uma das periferias da construção cruzada, funcionando, portanto, como recurso eficaz para que as bases sejam mais facilmente rastreadas.

Com base nessas concepções estabelecidas por Gonçalves (2005, 2006), examinamos se os CVs criados por Agamenon apresentam o mesmo comportamento de formações já existentes na língua e consagradas pelo uso, como, entre outras, 'apertamento' $(<<$ aperto + apartamento), 'paitrocínio' ( $<<$ pai + patrocínio) e 'showmício' $(<<$ show + comício $)$.

Nos CVs criados por Agamenon, não foi encontrado o padrão envolvendo palavras monossilábicas, o que não causa estranhamento, já que, como mostram Gonçalves e Almeida (2004), são poucas as formas cruzadas a partir de duas bases constituídas de uma sílaba apenas, como "pãe" (<< pai + mãe) e 'bau' $(<<$ bom + $\mathrm{mau}$ ). As construções existentes na coluna seguem a formação característica de vocábulos maiores, sendo "argentinha" e "boquetel" exemplos com características desse padrão.

O CV "argentinha" é formado pelas bases (P1) "Argentina" e (P2) "gentinha". As duas palavras (que abreviamos P) possuem como característica comum a acentuação numa sílaba fonologicamente idêntica $(<\mathrm{ti}>)$. Essa semelhança determina não só a interseção das palavras, como também a posição das bases no interior do cruzamento. Em decorrência de a sílaba $(<\mathrm{ti}>)$ ser tônica nas duas palavras, o CV preservará a pauta acentual de ambas as bases. Todavia, como a intenção do CV é menosprezar os cidadãos argentinos, (P1) é a cabeça lexical do novo vocábulo, já que 'gentinha' predica, pejorativamente, os cidadãos argentinos.

Processo semelhante ocorre com o CV "boquetel", formado pelas bases (P1) "boquete" e (P2) "coquetel". O ponto de quebra é 
realizado na sílaba comum às duas palavras (<que >). Sendo assim, aproveita-se toda a palavra "boquete" e é permitida uma correspondência não-idêntica entre o /b/ de "boquetel", o cruzamento, e o / k/ de "coquetel", uma das formas de base, tornando-se (P2) a cabeça lexical, pois essa levará seu acento para a nova palavra e será predicada por P1 ("boquete").

O padrão estrutural em que P1 e P2 são dessemelhantes fonicamente foi mais utilizado por Agamenon em referência aos prenomes do presidente - "Luís" e "Inácio". Observa-se, sobretudo na composição dos CVs envolvendo "Inácio", a realização do ponto de quebra na sílaba tônica das palavras-base. Conforme afirma Gonçalves (2005), não haverá descontinuidade morfológica nesses casos, pois a quebra será feita com base no melhor rastreamento das palavrasmatrizes. No CV "mensalácio", representativo de todas as fusões a partir do prenome "Inácio", percebe-se o processo estabelecido por Gonçalves: o ponto de quebra é realizado nas sílabas tônicas das palavras bases, conforme o observado no esquema em (01), a seguir:

(01)

Mensalão à Inácio mensalácio.

O padrão empregado nos cruzamentos envolvendo o sobrenome "Inácio" não foi o mesmo utilizado nos CVs que tratam de questões sociais. O CV "indiscroto" apresenta bases que se assemelham na seqüência fônica -scr- e na terminação -to: (P1) indiscreto e (P2) escroto. Diferente de "mensalácio", em que não há sobreposição, no CV "indiscroto" as duas palavras estão entranhadas de tão modo, que é simplesmente impossível postular segmentos individuais para cada uma: as seqüências em negrito são necessariamente ambimorfêmicas, como se vê em (02):

(02)

indiscreto à escroto à indiscroto

Os CVs produzidos em relação às pessoas presentes no governo Lula, em sua totalidade, estão inseridos no padrão em que P1 e P2 são semelhantes em uma das margens. O CV "Rouberto", formado pelas bases (P1) "roubo" e (P2) "Roberto", revela esse melhor 
rastreamento das palavras-matrizes proposto por Gonçalves. O ponto de quebra é realizado na margem esquerda ro-, compartilhada pelas duas bases, sendo que (P2) torna-se a cabeça da nova palavra por (a) levar seu acento lexical para o novo vocábulo e (b) ser o núcleo sintáticosemântico da forma resultante.

A forma "roubo" também se assemelha a "Roberto" na freqüente realização do ditongo <ou> como monotongo ("robô") e na presença de /b/ como segunda consoante da base. Admite-se, nesse caso, grande quantidade de material fonológico compartilhado, estando as duas bases entranhadas, a ponto de promover inúmeras situações de ambimorfemia. Processo idêntico ocorre com o CV "Merdonça". O compartilhamento também é realizado na margem esquerda, cabendo a (P1), "Mendonça", o papel de cabeça lexical do CV, por ter seu acento preservado e sofrer a predicação de P2 ('merda').

Algumas das construções realizadas por Agamenon se diferenciam do padrão estabelecido por Gonçalves para fusões lexicais. Essas construções são consideradas formações meramente analógicas. Formações analógicas são interpretadas como substituições sublexicais, uma vez que a palavra-alvo apresenta porção fonológica que coincide com a encontrada numa forma de livre-curso na língua e é a partir dessa identidade formal que se dá a incorporação.

A construção "bucetante", realizada por Agamenon, demonstra esse processo de incorporação lexical. Em português, existe o vocábulo "picante", porém a seqüência [pica-] não apresenta qualquer referência à forma chula para designar o órgão sexual masculino. Agamenon aproveita-se da seqüência [pica-] para incorporar o vocábulo "buceta", utilizado para designar de forma chula o órgão sexual feminino. Essa palavra promove o termo [pica-] à condição de radical da palavra, substituindo esse termo sublexicalmente.

Cruzamentos não podem ser analisados como substituições sublexicais porque duas palavras constituem imput à formação de uma terceira. No vocábulo "bucetante", o alvo é apenas uma das palavras e a interseção das bases é ocasionada pela reanálise intencional da formaimput. Observe a seguir o processo de formação analógica da forma "bucetante", em que os parênteses delimitam os constituintes Mwd abreviação da forma inglesa Morphological Word (Palavra Morfológica) - e Mwd*, expressão utilizada em referência a Complex Morphological Word (Palavra Morfológica Complexa): 
(03)

\begin{tabular}{|c|c|}
\hline (picante) & (comemorar) \\
\hline 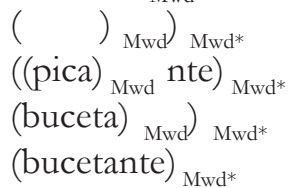 & 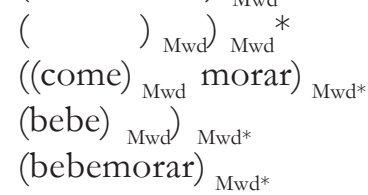 \\
\hline
\end{tabular}

Nas formações analógicas, constata-se a operação das bases em planos competitivos, enquanto nos CVs a junção dos vocábulos trabalha em planos alternativos. Cabe ainda mencionar que nas formações analógicas há a preservação da ordem linear dos elementos formadores, caracterizando um processo de reanálise morfológica.

\section{Considerações finais}

Observam-se, nos cruzamentos produzidos por Agamenon, os mecanismos necessários para o autor desenvolver seu humor e sarcasmo. Em sua coluna dominical no jornal O Globo, Agamenon utiliza essas construções com valores semânticos variados e as elabora com base no contexto social, econômico e / ou político, para ridicularizar a imagem pública dos personagens envolvidos.

A utilização dos CVs como forma de produzir o riso e de menosprezar pessoas com ampla circulação social mostrou-se totalmente eficaz. A fusão de palavras quase sempre com relação fonológica consegue criar o ambiente humorístico necessário para o desenvolvimento de idéias e atinge ainda o tom irônico exigido para a elaboração de um texto dinâmico, tão valorizado no mundo moderno.

Cabe ainda mencionar que os padrões estruturais utilizados por Agamenon na construção de cruzamentos apresentam o mesmo comportamento de formações já existentes, sendo o padrão mais utilizado em seus textos aquele que apresenta as bases P1 e P2, que não são totalmente diferentes do ponto de vista segmental.

Dessa forma, torna-se impossível ignorar o valor gramatical de cruzamentos como instrumentos para construção de textos atraentes para o leitor, considerando que o surgimento desses vocábulos parte, em sua maioria, de expressões dominadas pela população, conforme caracterizado nos textos de Agamenon. 


\section{Referências bibliográficas}

ALVES, I. M. Neologismo. São Paulo: Ática, 1989.

ARANHA, H.; MADUREIRA, M.. Agamenon Mendes Pedreira: O homem e o minto - Memórias de um Picareta Ético. Rio de Janeiro: Objetiva, 2002.

BASÍLIO, M.. Cruzamentos vocabulares: o fator humorfológico. Disponível em: <http://www.uff.br/assel-rio>. Acesso em: 11 set. 2005.

CUNHA, C. F.; CINTRA, C. L.. Gramática normativa da lingua portuguesa. Rio de Janeiro: MEC/FENAME, 1980.

GONÇALVES, C. A. V.. A ambimorfemia de cruzamentos vocabulares em português: uma abordagem por ranking de restrições. Revista da ABRALIN, v. 5, p. 169-184, 2006.

Blends lexicais em português: não-concatenatividade e correspondência. Veredas, Juiz de Fora, v. 14, n. 1, p. 16-35, 2005.

Processos morfológicos não-concatenativos: formato prosódico e latitude funcional. Alfa - Revista de Lingüística, Araraquara, v. 48 , n. 2 , p. 30-66, 2004.

.; ALMEIDA, M. L. L. Cruzamento vocabular no português brasileiro: aspectos morfo-fonologicos e semântico-cognitivos. Revista Portuguesa de Humanidades, Braga (Portugal), v. 8, n. 1, p. 151-170, 2004.

LIMA, C. H.. Gramática da língua portuguesa. Rio de Janeiro: José Olympio, 1975.

PIÑEROS, C. E. Word-blending as a case of non-concatenative morphology in spanish. Rutgers: Rutgers University, 2000. 
SÂNDALO, M. F. Morfologia. In: MUSSALIN, F.; BENTES, A. C. (Eds.). Introdução à Lingüistica. São Paulo: Cortez, 2001.

SANDMANN, A. J. Morfologia lexical. São Paulo: Contexto, 1990. 